\title{
One-step extracapsular cataract extraction and silicone oil-injection in the management of proliferative vitreoretinopathy
}

\author{
GHOLAM A PEYMAN AND LUIS R DE CORRAL \\ From the Department of Ophthalmology, University of Illinois at Chicago, Eye and Ear Infirmary, USA
}

SUMmaRY A combined technique of extracapsular cataract extraction and silicone oil injection is described. The anterior capsule is preserved to prevent movement of the silicone oil from the vitreous cavity to the anterior chamber. An anterior chamber tap ensures that the vitreous cavity is completely filled with silicone oil, while a peripheral iridectomy prevents postoperative pupillary block glaucoma.

In recent years silicone oil has been used in the treatment of complicated retinal detachments and proliferative vitreoretinopathy. ${ }^{1-7}$ Cataracts are often associated with these conditions. ${ }^{2}$

The surgical approach for proliferative vitreoretinopathy (PVR) includes a pars plana vitrectomy, membrane peeling, scleral buckling technique, and intravitreal injection of air or gas. If a cataract is present, a pars plana lensectomy may be done at the same time. When intravitreal silicone oil injection is used to tamponade the retina, preservation of the lens capsule is necessary to prevent postoperative anterior segment complications. ${ }^{8}$

We present a one-step procedure for extracapsular cataract extraction and silicone oil injection in the management of cataract and PVR. We believe this is the first report of this combined technique.

\section{Surgical technique}

A 4-mm infusion cannula is secured tightly to the sclera entering through the pars plana at the 3 o'clock or 9 o'clock position. A modified Shock phacofragmentor tip is introduced into the lens substance through a second pars plana sclerotomy (Fig. 1A) just posterior to the lens equator. The lens nucleus is fragmented and removed (Fig. 1B). Care is taken to not damage the anterior lens capsule. Removal of the lens cortical material and posterior lens capsule is completed with the Peyman vitrophage (Fig. 1C) by irrigation and aspiration and occasional cutting.

Correspondence to Dr Gholam A Peyman, 1855 W Taylor St, Chicago, IL 60612, USA.
Again extreme caution should be exercised to not damage the anterior lens capsule.

A third pars plana sclerotomy is prepared to introduce the light tube fibreoptic illuminator into the midvitreous. A complete vitrectomy is carried out until all traction has been relieved (Fig. 1D). Any epiretinal membranes present are segmented and removed, if possible. After the vitrophage is removed, the infusion cannula is connected to an air pump system, ${ }^{911}$ and a flute needle is introduced through the open sclerotomy to perform a complete air-fluid exchange (Fig. 1E). If any subretinal fluid is present, it can be drained internally at this time. Intraocular pressure is maintained in the 40 to 50 $\mathrm{mmHg}$ range to maintain adequate expansion of the globe. The light tube is removed and the sclerotomy is closed securely with appropriate suture material. The flute needle is removed and the sclerotomy is temporarily closed. A scleral buckle is placed to relieve traction and to support the retina.

A wide-bore (16 or 18 gauge) needle connected to a $10 \mathrm{ml}$ syringe containing the silicone oil is introduced through the temporarily closed sclerotomy. An air-silicone oil exchange is performed until a reflux of oil is seen in the infusion cannula (Fig. 1F). The anterior chamber is then tapped with a $\mathbf{3 0}$ gauge needle at the limbus, as silicone oil continues to enter the eye ${ }^{11}$ and to fill the vitreous cavity with the oil (Fig. 1G). The wide-bore needle and the infusion cannula are removed, and the sclerotomies are sutured securely.

A small 2 to $3 \mathrm{~mm}$ inferior limbal incision is made with a Zeigler knife. The anterior chamber is then 


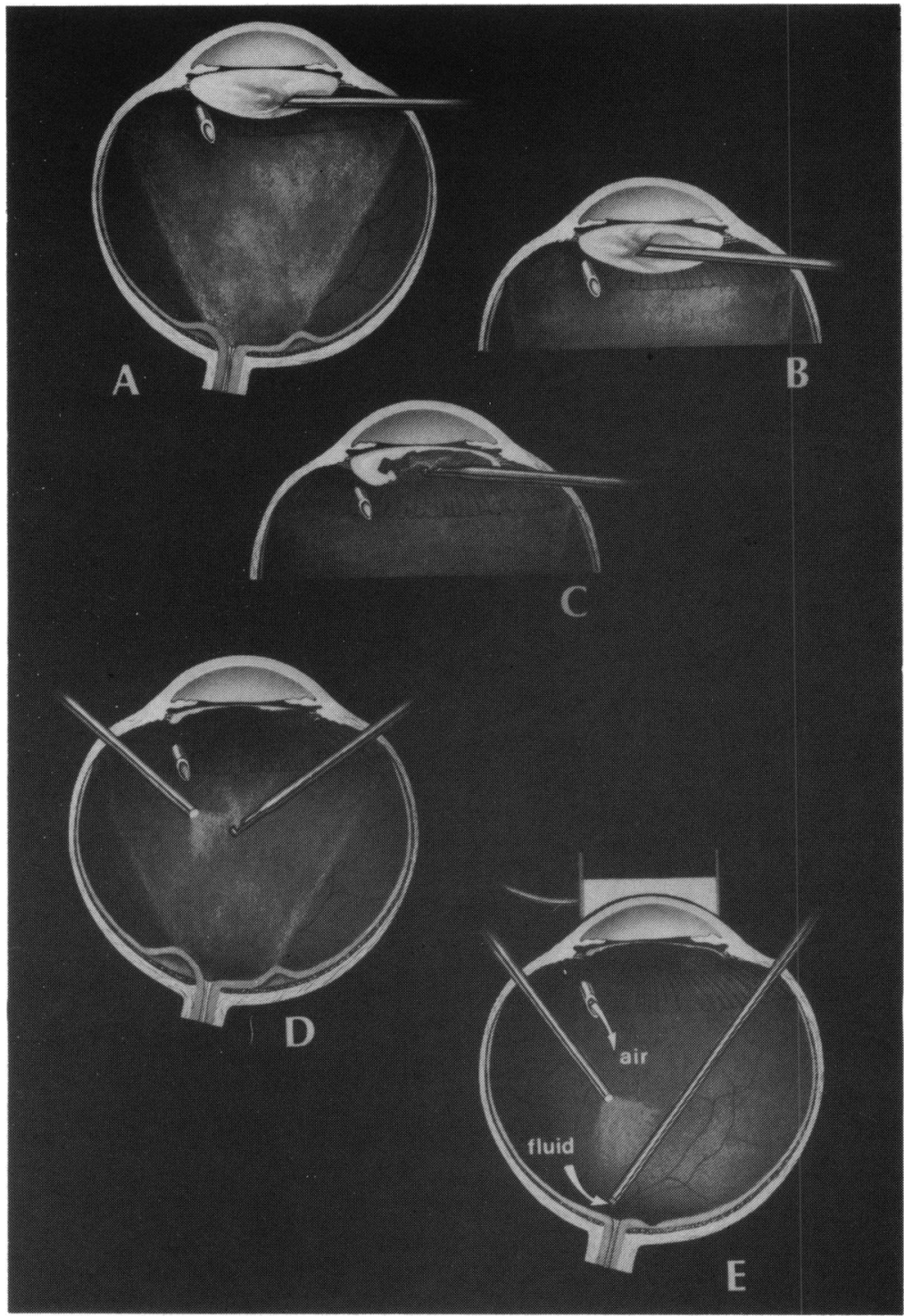

Fig. 1 Artist's rendering of the surgical technique. (A)

Introduction of the modified Shock phacofragmentor into the lens substance. (B) Fragmentation of the lens nucleus. (C) Lens cortex and posterior capsule are removed with the Peyman vitrophage. (D) $A$ complete vitrectomy is performed. (E) A complete air-fluid exchange is done with use of a flute needle.

filled with hyaluronic acid (Healon) through a 30 gauge cannula (Fig. 1H). Colibri forceps and Vannas scissors are used to perform a peripheral iridectomy through this incision (Fig. 1I). The iris is then repositioned and the hyaluronic acid is washed out with irrigation solution. The end result is an eye filled with silicone oil; the anterior chamber is protected from the oil by the preservation of the anterior lens capsule (Figs. 1J and $\mathrm{K}$ ).

\section{Preliminary results}

We have performed this combined procedure in seven patients with good anatomical results (Table 1). The follow-up has ranged between 4 and 8 months. The silicone oil remained confined to the vitreous cavity in all the patients except one. In this patient there was a $3 \mathrm{~mm}$ silicone oil bubble in the anterior chamber which had moved through a capsular rent from the vitreous cavity. This occurred on the first postoperative day and had remained stable. The postoperative gonioscopic findings in the patients with increased intraocular pressure are presented (Table 1). The anterior capsule has slightly opacified in two patients. A 1 to $2 \mathrm{~mm}$ central neodymium:YAG capsulotomy was performed in 
Fig. 1 (cont.) (F) Air-silicone oil exchange is performed with a largebore needle. (G) Anterior chamber is tapped with a 30 gauge needle to fill the eye completely with silicone oil. (H) Anterior chamber is filled with hyaluronic acid (Healon) (surgeon's view). (I) An inferior peripheral iridectomy is performed (surgeon's view). (J) Surgeon's view. (K) Eye is filled with silicone oil; anterior chamber is free of silicone oil owing to the presence of the anterior lens capsule.

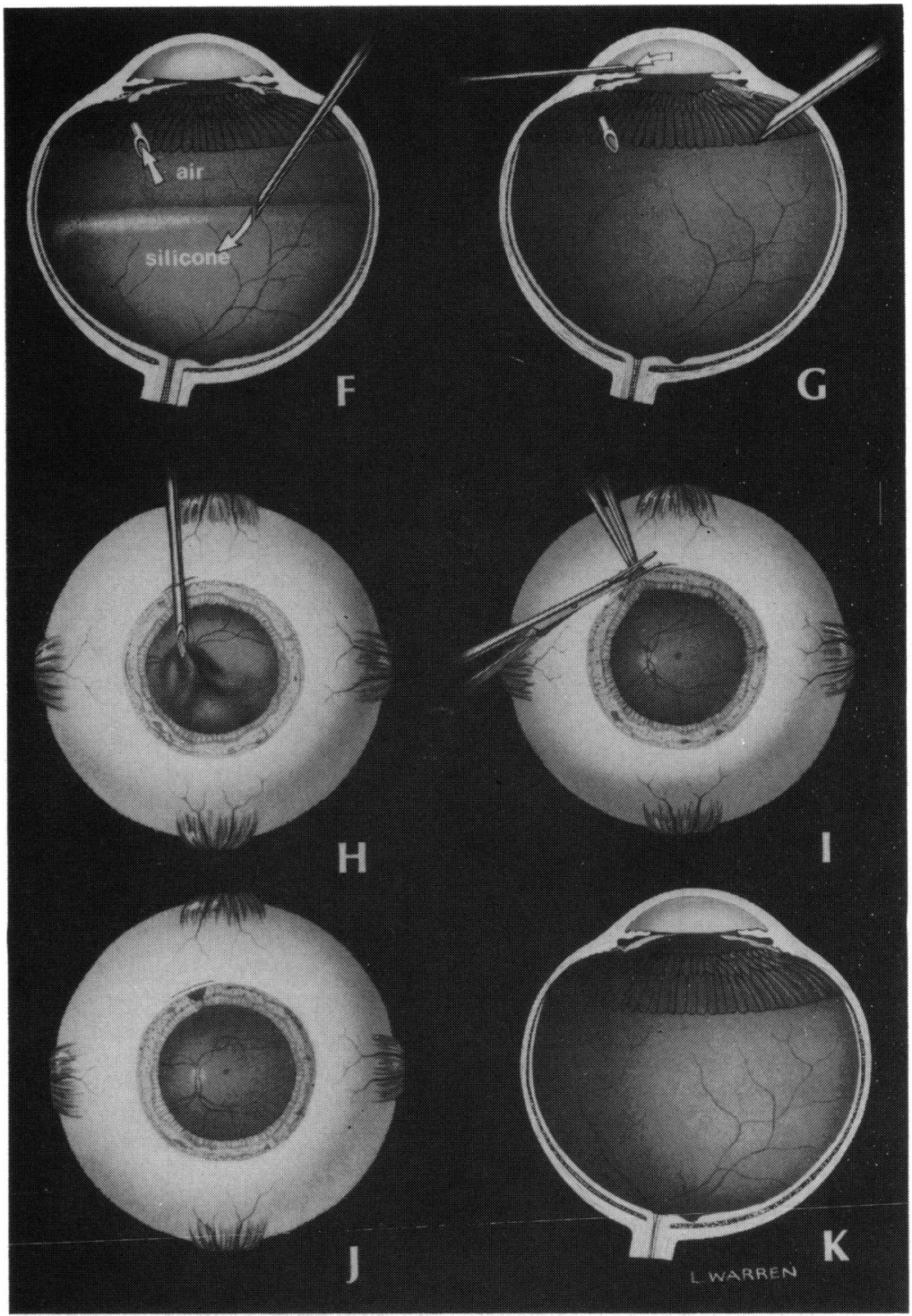

these patients without escape of the silicone from the vitreous cavity into the anterior chamber.

\section{Discussion}

We have previously described a technique for removing a cataract in a patient who has silicone oil in the eye (Cohen SB, Peyman GA, de Corral LR, unpublished data). The present technique combines the cataract extraction and the silicone oil injection in one procedure.

The salient feature of this method is the preservation of the anterior lens capsule, which prevents the displacement of the silicone oil from the vitreous cavity to the anterior chamber. This method decreases the postoperative complications most frequently seen in aphakic patients who have received intravitreal silicone oil, such as glaucoma and keratopathy. ${ }^{412}$ Four patients had increased intraocular pressure in the early postoperative period. Only one had silicone oil in the anterior chamber, which moved from the vitreous cavity through a capsular rent. The size of the oil bubble has not increased. In the other three the increased intraocular pressure could be due to peripheral anterior synechiae, inflammation, and hyaluronic acid in the anterior chamber (Table 1). 
Table 1 Summary of preliminary results in patients after combined extracapsular surgery and silicone oil injection

\begin{tabular}{|c|c|c|c|c|c|c|c|c|c|c|c|}
\hline \multicolumn{4}{|c|}{ CaseSex Age Diagnosis } & \multirow{2}{*}{$\begin{array}{l}\text { Preop } \\
\text { vision }\end{array}$} & \multirow{2}{*}{$\begin{array}{l}\text { Preop } \\
\text { IOP } \\
16 \mathrm{mmHg}\end{array}$} & \multirow{2}{*}{$\begin{array}{l}\begin{array}{l}\text { Postop } \\
\text { vision }\end{array} \\
\text { OD:HM }\end{array}$} & \multirow{2}{*}{$\begin{array}{l}\text { Result, } \\
\text { anatomical }\end{array}$} & \multirow{2}{*}{$\begin{array}{l}\text { Postop } \\
\text { IOP } \\
30 \mathrm{mmHg}\end{array}$} & \multirow{2}{*}{$\begin{array}{l}\text { Present } \\
\text { IOP } \\
18 \mathrm{mmHg}\end{array}$} & \multirow{2}{*}{$\begin{array}{l}\text { Treatment } \\
\text { T } 0.5 \%\end{array}$} & \multirow{2}{*}{$\begin{array}{l}\begin{array}{l}\text { Postoperative } \\
\text { gonioscopic } \\
\text { findings }\end{array} \\
\text { No oil in AC; } \\
\text { Healon in AC }\end{array}$} \\
\hline 1 & $\mathbf{M}$ & 56 & $\begin{array}{l}\text { Proliferative } \\
\text { diabetic retinopathy; } \\
\text { tractional RD OD }\end{array}$ & & & & & & & & \\
\hline 2 & $\mathbf{M}$ & 22 & $\begin{array}{l}\text { Retinal detachment } \\
\text { PVR, giant tear }\end{array}$ & OD:LP & $8 \mathrm{mmHg}$ & OD:LP & $\begin{array}{l}\text { Nasal retina } \\
\text { elevated; } \\
\text { temporal retina } \\
\text { attached }\end{array}$ & $9 \mathrm{mmHg}$ & $14 \mathrm{mmHg}$ & - & No oil in AC \\
\hline 3 & $\mathbf{M}$ & 34 & $\begin{array}{l}\text { Car battery } \\
\text { explosion trauma } \\
\text { OD, RD }\end{array}$ & OD:LP & $7 \mathrm{mmHg}$ & OD:6/50 & $\begin{array}{l}\text { Retina } \\
\text { attached }\end{array}$ & $36 \mathrm{mmHg}$ & $6 \mathrm{mmHg}$ & - & $\begin{array}{l}\text { Oil in AC } \\
\text { through } \\
\text { capsular rent; } \\
\text { PAS }\end{array}$ \\
\hline 4 & $F$ & 21 & $\begin{array}{l}\text { Proliferative } \\
\text { retinopathy } \\
\text { secondary to } \\
\text { sarcoid; cataract } \\
\text { tractional retinal } \\
\text { detachment }\end{array}$ & OD:HM & $5 \mathrm{mmHg}$ & OD:HM & $\begin{array}{l}\text { Attached } \\
\text { nasally, } \\
\text { traction over } \\
\text { arcades }\end{array}$ & $18 \mathrm{mmHg}$ & $8 \mathrm{mmHg}$ & - & No oil in AC \\
\hline 5 & $\mathbf{M}$ & 45 & $\begin{array}{l}\text { Trauma, macular } \\
\text { hole, total RD,PVR; } \\
\text { angle recession and } \\
\text { scarring } 360^{\circ}\end{array}$ & OS:HM & $4 \mathrm{mmHg}$ & OS:6/120 & $\begin{array}{l}\text { Retina } \\
\text { attached }\end{array}$ & $37 \mathrm{mmHg}$ & $23 \mathrm{mmHg}$ & $\begin{array}{l}\text { T0.5\% } \\
\text { acetazolamide } \\
250 \mathrm{mg}\end{array}$ & $\begin{array}{l}\text { No oil in AC; } \\
360^{\circ} \text { angle } \\
\text { recession, } \\
\text { PAS }\end{array}$ \\
\hline 6 & $\mathrm{~F}$ & 55 & $\begin{array}{l}\text { Proliferative } \\
\text { diabetic retinopathy; } \\
\text { retinal detachment }\end{array}$ & OD:HM & $14 \mathrm{mmHg}$ & OD:LP & $\begin{array}{l}\text { Retina } \\
\text { attached }\end{array}$ & $40 \mathrm{mmHg}$ & $6 \mathrm{mmHg}$ & $\mathrm{T} 0 \cdot 5 \%$ & $\begin{array}{l}\text { No oil in AC; } \\
\text { inflammation }\end{array}$ \\
\hline 7 & $\mathbf{M}$ & 74 & $\begin{array}{l}\text { Proliferative } \\
\text { diabetic retinopathy } \\
\text { vitreous } \\
\text { haemorrhage }\end{array}$ & OD:HM & $17 \mathrm{mmHg}$ & OD: $6 / 600$ & $\begin{array}{l}\text { Retina } \\
\text { attached }\end{array}$ & $15 \mathrm{mmHg}$ & $11 \mathrm{mmHg}$ & - & No oil in AC \\
\hline
\end{tabular}

$\mathrm{AC}=$ anterior chamber. $\mathrm{PAS}=$ peripheral anterior synechiae. $\mathrm{PVR}=$ proliferative vitreoretinopathy. $\mathrm{T}=$ timolol. $\mathrm{RD}=$ retinal detachment. $\mathrm{CF}=$ counting fingers. $\mathrm{HM}=$ hand motion. $\mathrm{LP}=$ light perception.

The air pump helps to keep the retina attached and the globe expanded so that the silicone oil injection can be accomplished successfully. When the oil injection is combined with the anterior chamber tap, the vitreous cavity can be filled completely with silicone oil. This step is important to prevent an incomplete fill with silicone.

An inferior peripheral iridectomy is done to decrease the possibility of pupillary block glaucoma.${ }^{13}$ Because silicone oil floats in an aqueous medium, a superior peripheral iridectomy could be blocked by the oil.

Although the mean follow-up time of our patients is short, the preliminary results are encouraging. The cornea has remained clear in all our patients undergoing this procedure. The postoperative rise in intraocular pressure has been managed medically. If any of the preserved anterior capsules become opacified, a small (1 to $2 \mathrm{~mm}$ ) central capsulotomy with the neodymium:YAG laser may improve the patient's visual acuity. A high viscosity silicone oil $(12500 \mathrm{cSt})$ does not move readily from the vitreous cavity through a small capsular opening into the anterior chamber.

Supported in part by core grant 1 P3EY01792 from the National Eye Institute, Bethesda, MD.

\section{References}

1 Cibis P, Becker B, Okun E, Canaan S. The use of liquid silicone in retinal detachment surgery. Arch Ophthalmol 1962; 68: 590-9.

2 Watzke RC. Silicone retinopiesis for retinal detachment. Arch Ophthalmol 1967; 77: 185-96.

3 Scott JD. The treatment of massive vitreous retraction by the separation of pre-retinal membranes using liquid siliconc. Mod Probl Ophthalmol 1975; 15: 285-90.

4 Grey RHB, Leaver PK. Results of silicone oil injection in massive preretinal retraction. Trans Ophthalmol Soc UK 1977; 97: $238-41$.

5 Gonvers M. Temporary use of intraocular silicone oil in the treatment of detachment with massive periretinal proliferation. Ophthalmologica 1982; 184: 210-8.

6 Haut J, Van Effenterre G, Flamand M. Treatment of macular hole retinal detachment with silicone oil, with or without argon laser photocoagulation. Ophthalmologica 1983; 187: 225-8.

7 Gonvers M. Temporary use of silicone oil in the treatment of special cases of retinal detachment. Ophthalmologica 1983; 187: 202-9. 
8 Sternberg P Jr, Hatchell DL, Foulks GN, Landers MB III. The effect of silicone oil on the cornea. Arch Ophthalmol 1985; 103: 90-4.

9 Bruckner AJ, Hoffman ME, Nevyas HJ, Wulc AE. New instrumentation for fluid-aid exchange. Retina 1983 ; 3: 135-6.

10 Hueneke RL, Aaberg TM. Instrumentation for continuous fluidair exchange during vitreous surgery. Am J Ophthalmol 1983; 96: $547-8$.
11 de Corral LR, Peyman GA. Silicone oil injection in aphakic cyes: A modified technique. Ophthalmic Surg in press.

12 Alexandridis E, Danicl H. Results of silicone oil injection into the vitreous. Dev Ophthalmol 1981; 2: 24-7.

13 Ando F. Intraocular hypertension resulting from pupillary block by silicone oil. Am J Ophthalmol 1985; 99: 87-8.

Accepted for publication 10 October 1985. 